\title{
Conservação de sementes de abóbora através de secagem convectiva
}

\section{Virgínia Mirtes de Alcântara Silva ${ }^{l}$; Newton Carlos Santos ${ }^{l}$; Sâmela Leal Barros ${ }^{l}$; Raphael Lucas Jacinto Almeida ${ }^{2}$; Victor Herbert de Alcântara Ribeiro ${ }^{\prime}$; Mylena Olga Pessoa Melo ${ }^{1}$}

${ }^{1}$ Universidade Federal de Campina Grande, virginia.mirtes2015@gmail.com, newtonquimicoindustrial@gmail.com, samelaleal7@gmail.com, victor_herbert@gmail.com, mylenaopm@gmail.com; ${ }^{2}$ Universidade Federal do Rio Grande do Norte, raphaelqindustrial@gmail.com.

RESUMO: A secagem é uma forma de minimizar perdas, possibilitando o transporte, o armazenamento e aumentando a vida útil do produto. Portanto, o presente trabalho tem como objetivo realizar a secagem convectiva estudando o ajuste de curvas da secagem para sementes de abóbora em diferentes temperaturas. A secagem foi realizada em estufa de circulação de ar com velocidade de $1,5 \mathrm{~m} . \mathrm{s}^{-1}$, nas temperaturas de 60 e $80{ }^{\circ} \mathrm{C}$; e os modelos empíricos (Page, Lewis e Wing\& Singh), foram ajustados aos dados experimentais. Dentro os modelos empíricos aplicados o de Lewis e Page, apresentaram bons parâmetros estatísticos, no entanto, o modelo de Lewis foi considerado o de melhor ajuste devido a simplicidade de sua equação. Contudo, a secagem e uma técnica eficiente na conservação das sementes de abóbora, pois reduzem o teor de água aumentando a vida útil das mesmas.

PALAVRAS-CHAVE: Curcubitamoschata; Lewis; Modelos empíricos.

\section{INTRODUÇÃO}

O cultivo de abóboras (Curcubitamoschata) é realizado frequnetemnte em pequenas propriedades rurais e em cultivos comerciais; seu uso na alimentação humana é usada no preparo de doces em calda ou em pasta, pratos salgados, ensopados ou cozidos (RESENDE et al., 2013). Partes não convencionais como os grãos de abóbora podem ser utilizadospara consumo na forma de farinha ou simplesmente torrados; também podem ser destinados a produção de óleo e como ingrediente culinário (DIÓGENES et al., 2013).

Diversos estudos têm destacado a importância nutricional, funcional e tecnológica da semente de abóbora. Essas sementes são ricas em lipídios, proteínas, aminoácidos, fibras e compostos antioxidantes (AMARAL et al., 2019). E a sua exploração comercial exige conhecimentos sobre a armazenabilidade e cuidados na secagem para garantir a qualidade e preservação dos componentes do produto (DIÓGENES et al., 2013).

A secagem é uma processo essencial para a indústria de sementes e subprodutos a fim de preservar a sua qualidade e estabilidade, por meio da redução do seu teor de umidade. Nesta perspectiva, a secagem convectiva é um tecnologia amplamente utilizada e adequada para subprodutos, sendo geralmente usada na desidratação e conservação de materiais biológicos (LEITE et al., 2019).

De acordo com o exposto, o objetivo do presente trabalho foi realizar a secagem convectiva estudando o ajuste de curvas da secagem para sementes de abóbora em diferentes temperaturas.

\section{MATERIAL E MÉTODOS}

Para o desenvolvimento deste trabalho foram utilizadas sementes de abóbora híbrida (Cucurbita moschata) adquiridas na feira central da cidade de Campina Grande, Paraíba. Os experimentos foram realizados no Laboratório de Secagem da Unidade Acadêmica de Engenharia de Alimentos da Universidade Federal de Campina Grande (UFCG).

A cinética de secagem foi realizada em estufa de circulação de ar com velocidade de $1,5 \mathrm{~m} \cdot \mathrm{s}^{-1}$, nas temperaturas de 60 e $80^{\circ} \mathrm{C}$, nas quais as sementes de abóbora foram distribuídas uniformemente em bandejas formando uma camada fina (aproximadamente 100g de sementes).Os dados experimentais foram expressos em termos de razão de teor de água $\left(X^{*}\right)$, dada pela relação entre as diferenças de teores de água no tempo, t, e teor de água de equilíbrio $\left(X(\mathrm{t})-X_{\text {eq }}\right)$ e teores de água inicial e de equilíbrio $\left(X_{i}-X_{e q}\right)$. Como descrito na Equação 1.

$$
X^{*}(t)=\frac{X(t)-X_{e q}}{X_{i}-X_{e q}}
$$

Sendo que: $X^{*}=$ razão de teor de água (adimensional); $X_{e q}=$ teor de água de equilíbrio (base seca); $X(\mathrm{t})=$ teor de água (base seca); $X_{i}=$ teor de água inicial (base seca).

As funções empíricas $f(\mathrm{t}, \mathrm{a}, \mathrm{b})$ e as expressões matemáticas para taxa de secagem em função do tempo apresentadas na Tabela 1, foram ajustadas aos conjuntos de dados experimentais, usando regressão não linear através do Software de Ajuste de Curvas LAB Fit (SILVA;SILVA, 2008). Os resultados, dos modelos empíricos, foram avaliados através dos indicadores estatísticos qui-quadrado, $\chi^{2}$ (Equação 2 ) e coeficiente de determinação, $\mathrm{R}^{2}$. 
SILVA, V. M. A. et al. Conservação de sementes de abóbora através de secagem convectival. In: II Congresso Paraibano de Agroecologia \& IV Exposição Tecnológica, 2019. Anais... Caderno Verde de Agroecologia e Desenvolvimento Sustentável, Pombal, v. 9, n.7, e-7098, 2019.

Tabela 1. Modelos empíricos e taxa de secagem para descrição da cinética de secagem.

\begin{tabular}{lcc}
\hline Modelos & Equação empírica & Taxa de secagem \\
\hline Page & $X^{*}=e^{-a t^{b}}$ & $d X^{*} / d t=-a b e^{b-1} e^{-a t^{b}}$ \\
Lewis & $X^{*}=e^{-a t}$ & $d X^{*} / d t=a e^{-a t}$ \\
Wang \& Singh & $X^{*}=1+a t+b t^{2}$ & $d X^{*} / d t=-(a+2 b t)^{2}$ \\
\hline
\end{tabular}

$$
\chi^{2}=\frac{\sum_{i=1}^{N}\left(X_{\exp ,}^{*}-X_{p r e, i}^{*}\right)^{2}}{N-n}
$$

Onde: $\chi^{2}$ é a função qui-quadrado; $X_{\text {exp, } i}^{*}$ : é a razaõ de umidade experimental; $X_{\text {pre }, i}^{*}$ : é a razão de umidade prevista pelo modelo; $\mathrm{N}$ é o número de dados experimentais; e n é o número de coeficientes e constantes do modelo.

\section{RESULTADOS E DISCUSSÃO}

$\mathrm{Na}$ Tabela 2, estão apresentados os resultados obtidos para os modelos empíricos aplicados a cinética de secagem das sementes de abóbora, assim como os indicadores estatísticos, coeficiente de determinação $\left(R^{2}\right)$ e quiquadrado $\left(\chi^{2}\right)$.

Tabela 2 - Parâmetros obtidos para os modelos aplicadas a cinética de secagem da sementes de abóbora.

\begin{tabular}{|c|c|c|c|c|c|}
\hline \multirow{2}{*}{ Modelos } & \multirow{2}{*}{$\mathrm{T}\left({ }^{\circ} \mathrm{C}\right)$} & \multicolumn{2}{|c|}{ Parâmetros } & \multirow{2}{*}{$\mathrm{R}^{2}$} & \multirow{2}{*}{$\chi^{2}$} \\
\hline & & $a$ & $b$ & & \\
\hline \multirow[b]{2}{*}{ Page } & 60 & 0,02856 & 0,9358 & 0,9903 & 0,002268 \\
\hline & 80 & 0,02805 & 1,0394 & 0,9961 & 0,007879 \\
\hline \multirow[b]{2}{*}{ Lewis } & 60 & 0,02279 & - & 0,9906 & 0,002401 \\
\hline & 80 & 0,03195 & - & 0,9956 & 0,002732 \\
\hline \multirow[b]{2}{*}{ Wang \& Singh } & 60 & $-0,008780$ & $0,1583 \times 10^{-4}$ & 0,8227 & 0,731720 \\
\hline & 80 & $-0,012602$ & $0,3123 \times 10^{-4}$ & 0,8121 & 0,682255 \\
\hline
\end{tabular}

Observa-se a partir dos parâmetros estatísticos, que o coeficiente de determinação $\left(\mathrm{R}^{2}\right)$ para os modelos empíricos de Page e Lewis, foram superiores a $0,99\left(\mathrm{R}^{2}>0,99\right)$ e para o modelo de Wang \& Singh este mesmo parâmetro estatístico variou de 0,8121 a 0,8227 quando a temperatura variou de 60 a $80{ }^{\circ} \mathrm{C}$. Portanto, não sendo considerado como um modelo de ajuste satisfatório.

Segundo Silva et al. (2019) para que seja possível afirmar que um modelo apresenta bom ajuste aos dados experimentais, é essencial que além do $\mathrm{R}^{2}$ próximo a 1,00 que o qui-quadrado $\left(\chi^{2}\right)$ possua valores mínimos. Dentre os modelos estudados, o modelo de Page e de Lewis apresentaram bons ajustes pois possuem $\mathrm{R}^{2}$ superiores a 0,99 e baixos valores de qui-quadrado $\left(\chi^{2}\right)$. No entanto, o modelo de Lewis, foi considerado como o modelo mais eficiente na descrição do processo de secagem de sementes de abóbora, pois além do bom ajuste observa-se simplicidade na sua equação.

Santos et al. (2019a) ao desidratarem grãos de arroz preto nas temperaturas de 40, 50, 60, 70 e $80{ }^{\circ} \mathrm{C}$, concluíram que o modelo de Page foi o que melhor se ajustou aos dados experimentais.

Silva et al. (2019) em seus estudos com grãos de feijão branco observaram que o modelo de Handerson \& Pabis foi o que melhor se ajustou aos dados experimentais nas temperaturas variando de 40 a $80{ }^{\circ} \mathrm{C}$.

Em relação ao parâmetros " $a$ " dos três modelos aplicados observa-se que para os modelos de Page e Wang \& Singh reduziu com aumento da temperatura de $60^{\circ} \mathrm{C}$ para $80^{\circ} \mathrm{C}$, apenas o modelo de Lewis apresentou comportamento diferente. E para o parâmetro " $b$ " o mesmo obteve comportamento semelhante onde o mesmo teve aumento na medida em que se elevou a temperatura do ar de secagem. Comportamento semelhante para os parâmentros a e b também foi observado por Santos et al. (2019b) ao secagem pimentão com variação da temperatura de 50 a $80{ }^{\circ} \mathrm{C}$. 
SILVA, V. M. A. et al. Conservação de sementes de abóbora através de secagem convectival. In: II Congresso Paraibano de Agroecologia \& IV Exposição Tecnológica, 2019. Anais... Caderno Verde de Agroecologia e Desenvolvimento Sustentável, Pombal, v. 9, n.7, e-7098, 2019.

Pode observar na Figura 1 que, o estudo da cinética de secagem mostra que o acréscimo da temperatura favorece a transferência de massa, diminuindo a umidade de equilíbrio dinâmico e o tempo de secagem. O tempo de secagem variou de 330 a 450 min quando a temperatura variou de 80 a $60{ }^{\circ} \mathrm{C}$, respectivamente. Segundo Santos et al. (2019c) esse fenômeno se deve ao fato de que em temperaturas mais elevadas a energia cinética das moléculas de água é acelerada em virtude da maior energia de aquecimento (DENG et al., 2017; ARAL; BEŞE, 2016).

Figura 1. Cinética de secagem simulada usando o modelo empírico de Lewis para as temperaturas de 60 e $80{ }^{\circ} \mathrm{C}$.
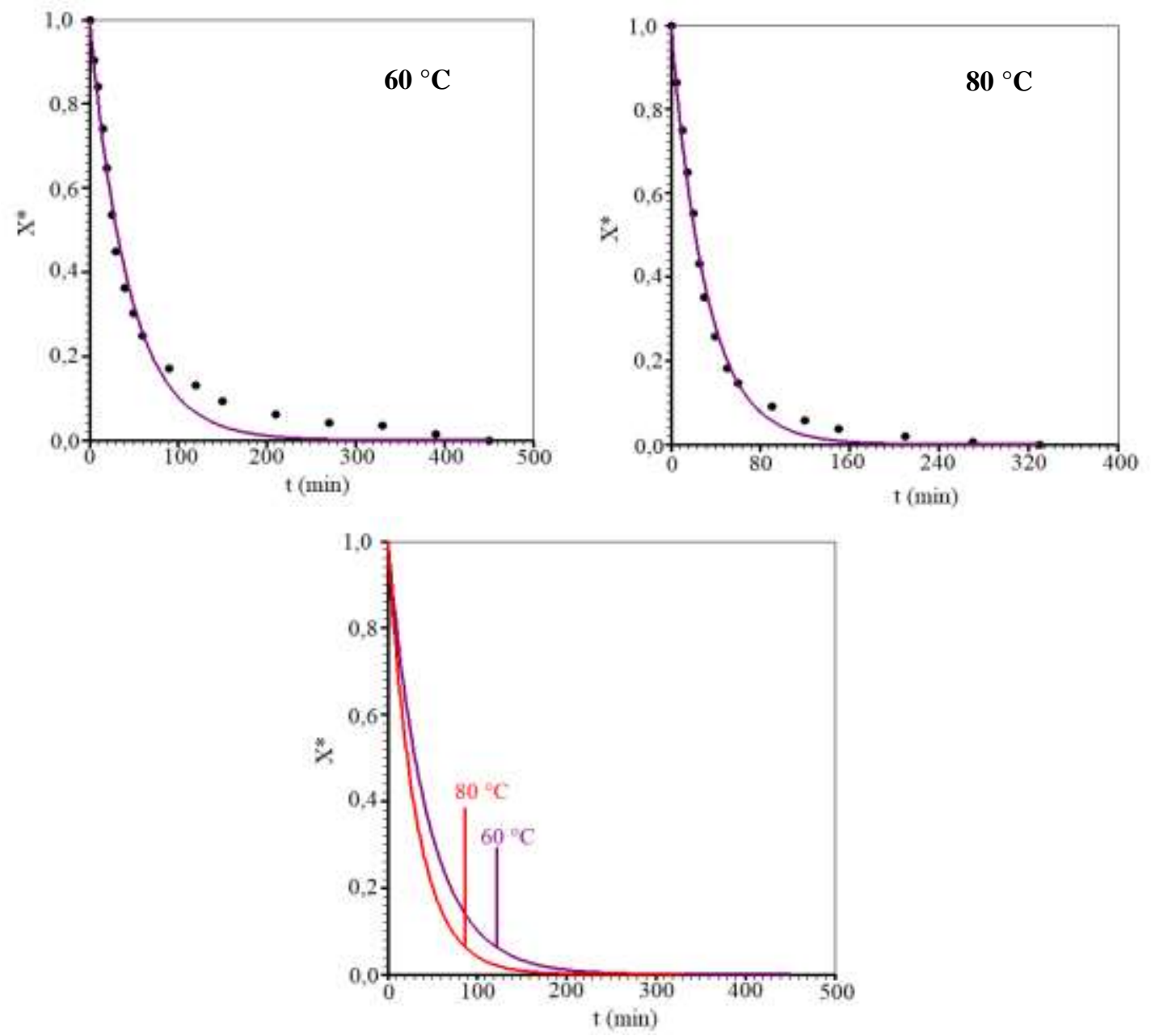

Estão descritas na Figura 2, as curvas que representam as taxas de secagem em função do tempo para as duas temperaturas aplicadas $\left(60\right.$ e $\left.80{ }^{\circ} \mathrm{C}\right)$ em razão do teor de umidade do produto descrita pelo modelo de Lewis. Portanto, foi verificado o decréscimo da taxa de secagem $(-\mathrm{dX} * / \mathrm{dt})$ desde o instante inicial até o final do processo, que ocorre quando a taxa de secagem apresenta valor nulo, representado que foi atingida uma condição de equilíbrio.

Figura 2.Taxa de secagem calculada usando a expressão obtida através do modelo de Lewis para as temperaturas de 60 e $80{ }^{\circ} \mathrm{C}$

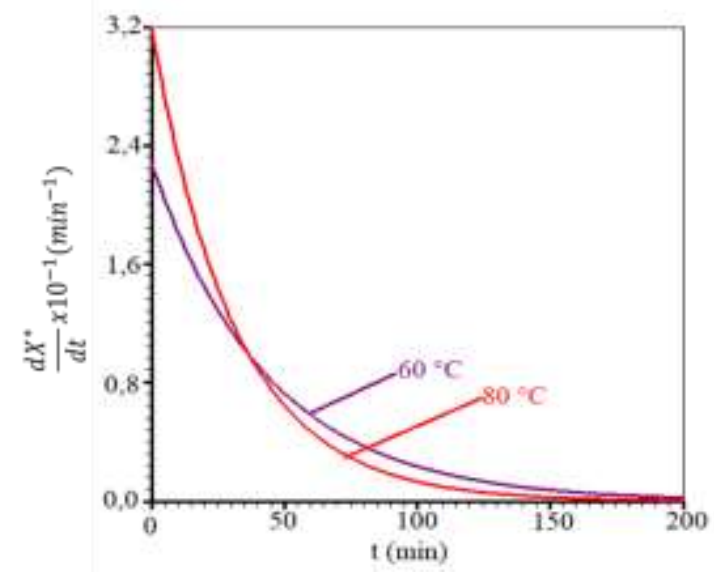


SILVA, V. M. A. et al. Conservação de sementes de abóbora através de secagem convectival. In: II Congresso Paraibano de Agroecologia \& IV Exposição Tecnológica, 2019. Anais... Caderno Verde de Agroecologia e Desenvolvimento Sustentável, Pombal, v. 9, n.7, e-7098, 2019.

Foi observado que a taxa de secagem é proporcional a razão de umidade e as maiores taxas de secagem são observadas nos instantes iniciais, através da elevação do pico (período de indução). Segundo Ribeiro et al. (2019), a elevação da temperatura do ar de secagem desenvolve maior gradiente de umidade entre o produto e o ar, acarretando maior taxa de remoção de água, independentemente do tipo do material utilizado.

\section{CONCLUSÕES}

A secagem é uma técnica eficiente na conservação das sementes de abóbora, pois proporciona a redução do teor de água do produto, aumentando sua estabilidade durante o armazenamento. Dentre os modelos empíricoso de Lewis foi considerado o de melhor ajuste devido a simplicidade de sua equação. O tempo de secagem varia de 330 a 450 minutos, reduzindo o tempo de secagem com o aumento da temperatura.

\section{REFERÊNCIAS}

AMARAL, L. F.; FERREIRA, I. M.; SANTOS, L. V. N.; SILVA, A. M. O.; FAGUNDES, A. A.; CARVALHO, M. G. Biscuit with spices and corn flours and pumpkin seed: development and quality assessment. Ciências e Tecnologia de Alimentos, v.14, e33380, p. 1-17, 2019.

ARAL, S.; BEŞE, A. V. Convective drying of hawthorn fruit (Crataegus spp.): Effect of experimental parameters on drying kinetics, color, shrinkage, and rehydration capacity. Food Chemistry, v.210, n.1, p.577-584, 2016.

DENG, L. Z.; YANG, X. H.; MUJUMDAR, A. S.; ZHAO, J. H.; WANG, D.; ZHANG, Q.; WANG, J.; GAO, Z. J.; XIAO, H. W. Red pepper (Capsicum annuum L.) drying: Effects of different drying methods on drying kinetics, physicochemical properties, antioxidant capacity, and microstructure. Drying Technology, v.36, n.8, p.893-907, 2017.

DIÓGENES, A. M. G.; QUEIROZ, A. J. M.; FIGUEIRÊDO, R. M. F.; SANTOS, D. C. Drying kinetic of pumpkins grains. RevistaCaatinga, v. 26, n. 1, p. 71-80, 2013.

LEITE, D. D. F.; QUEIROZ, A. J. M.; FIGUEIRÊDO, R. M. F.; LIMA, L. S. L. Mathematical drying kinetics modeling of jackfruit seeds (Artocarpusheterophyllus Lam.). Revista Ciência Agronômica, v. 50, n. 3, p. 361-369, 2019.

RESENDE, G. M.; BORGES, R.M.E.; GONÇALVES, N. P. S. Produtividade da cultura da abóbora em diferentes densidades de plantio no Vale do São Francisco. Horticultura Brasileira, v.31, p.504-508, 2013.

RIBEIRO, V. H. A.; ALMEIDA, R. L. J.; SANTOS, N. C.; BARROS, S. L.; NASCIMENTO, A. P. S. Mathematicalmodelingofappledryingkinetics. Revista Higiene Alimentar, v.33, n.288/289, p.3474-3478, 2019.

SANTOS, D. C.; LEITE, D. D. F.; LISBÔA, J. F.; FERREIRA, J. P. L.; SANTOS, F. S.; LIMA, T. L. B.; FIGUÊIREDO, R. M. F.; COSTA, T. N. Modellingandthermodynamicpropertiesofthedryingofacurislices. BrazilianJounalofFoodTechonology, v.22, e 2018031, 2019c.

SANTOS, N. C.; BARROS, S. L.; SILVA, S. N.; RIBEIRO, V. H. A.; MELO, M. O. P.; SILVA, W. P.; ALMEIDA, R. L. J.; PEREIRA, T. S.; ARAÚJO, A. J. B.; GOMES, J. P.; NASCIMENTO, A. P. S.; SILVA, V. M. A.; VIEIRA, D. M. Physico-chemicalcharacterizationandkineticsofdryingoforganicyellowbellpepper $\quad$ (Capsicumannuum L.). AfricanJournalofAgriculturalResearch, v. 14, n. 29, p. 1247-1253, 2019b.

SANTOS, N. C.; SIlVA, W. P.; BARROS, S. L.; ARAÚJO, A. J. B.; GOMES, J. P.; ALMEIDA, R. L. J.; NASICMENTO, A. P. S.; ALMEIDA, R. D.; SILVA, C. M. D. P. S.; QUEIROZ, A. J. M.; FIGUEIRÊDO, R. M. F. StudyonDryingof Black Rice (Oryza sativa L.) Grains: Physical-Chemical and Bioactive Quality. Journal of Agricultural Science, v. 11, n. 9, p. 203-212, 2019a.

SILVA, E. C. O.; SILVA, W. P.; GOMES, J. P.; SILVA, C. M. D. P. S.; ALEXANDRE, H. V.; FARIAS, V. S. O.; MELO, B. A.; QUEIROZ, A. J. M.; FIGUÊIREDO, R. M. F. Drying of Albedo and Whole Peel of Yellow Passion Fruit. Journal of Agricultural Science, v. 11, n.6, p. 501-509, 2019. https://doi.org/10.5539/jas.v11n6p501

SILVA, V. M. A.; RIBEIRO, V. H. A.; SANTOS, N. C.; BARROS, S. L.; NASCIMENTO, A. P. S.; ARAÚJO, A. J. B. Modelagem matemática da cinética aplicada na secagem do feijão branco (Phaseolusvulgaris). In: Francisco et al. (Org.). Caderno de Ciência Pesquisa e Inovação. EPGRAF, Campina Grande-PB, v.2, n.1, p.97-106, 2019.

SILVA, W. P.; SILVA, C. M. D. P. S. LAB Fit Curve Fitting Software (Nonlinear Regression and Treatment of Data Program) V 7.2.50 (2008), online, available from world wide web: <www.labfit.net>, date of access: 2019-March-28. 
SILVA, V. M. A. et al. Conservação de sementes de abóbora através de secagem convectival. In: II Congresso Paraibano de Agroecologia \& IV Exposição Tecnológica, 2019. Anais... Caderno Verde de Agroecologia e Desenvolvimento Sustentável, Pombal, v. 9, n.7, e-7098, 2019.

\section{AGRADECIMENTOS}

Apoio financeiro: Fundação de Apoio à Pesquisa do Estado da Paraíba - FAPESQ. 